\title{
ESTADO, MERCADO Y ORGANISMOS \\ NO LUCRATIVOS: \\ EL PUNTO DE VISTA DE UN ECONOMISTA DE EMPRESA
}

Dra. Clara Caselli

1. El mercado no existe por naturaleza, el mercado es el resultado de una actividad humana

El mercado no se encuentra por naturaleza, pues es el resultado de la actividad de los hombres en el curso del tiempo. El mercado es algo humano, historico, cultural.

Todos conocen la definición de mercado: un punto de encuentro de compradores y vendedores, que compran y venden bienes y servicios. En esta definición hay un punto que querría subrayar: para intercambiar cosas los individuos tienen que comunicarse entre ellos. El intercambio de bienes presupone un intercambio de informaciones. En un mercado que funciona bien este proceso es fácil, rápido y eficiente.

La conclusión es que el mercado no existe por naturaleza, pues es el resultado de una experiencia histórica, la experiencia de individuos que poseen bienes, es decir algo interesante para otros individuos, y que por lo tanto se relacionan entre ellos. El mercado es una forma de relación humana, una construcción hecha por los hombres, que está basada en un complejo de reglas que definen cómo las relaciones de intercambio de bienes tienen que ser desarrolladas.

Por lo tanto, el mercado como estructura de relación y comunicación implica que el aspecto normativo-jurídico sea tomado en cuenta desde el inicio, porque no es simplemente complementario sino constitutivo, esencial para la existencia del mercado mismo. No podria existir un mercado sin reglas, así como no pueden existir relaciones interpersonales sin reglas.

Pero, hay reglas y reglas. ¿Cómo tienen que ser las reglas del mercado?

\section{El mercadoy sus fracasos}

Muchos economistas (hoy como en el pasado) opinan que el libre mercado es la forma más eficiente para organizar la vida económica de un país y que el 
estado no tiene que poner reglas porque si todos los sujetos económicos persiguen su interés, la consecuencia es el bienestar general, gracias a la intervención de una "mano invisible" que equilibra todo y transforma los egoismos en virtudes.

¿Pero, es así? No, no es asi. Muchas veces el mercado fracasa y sus fracasos son debidos a varios motivos. Limitémonos a los más importantes.

Primero. Hay bienes de naturaleza pública. El mercado no logra producir todos los bienes públicos que necesitan, es decir, los bienes para los cuales no hay competencia ni rivalidad entre los individuos porque el uso por parte de uno no excluye el uso por parte de otros. Por ejemplo, este es el caso de las carreteras, de la defensa, de la justicia. No existe un mercado de esos bienes, porque nadie puede ser excluido.

Segundo. Hay bienes sin precio. A veces la actividad económica de una empresa produce consecuencias sobre otras empresas o personas, pero estos efectos no pueden ser medidos, porque no hay precios que puedan medirlos. Este es el caso de la contaminación del medio ambiente: hay un daño económico, pero no hay un precia

Tercero. A veces el mercado no funciona porque las informaciones relativas a la calidad, a la cantidad y al precio de los bienes no circulan bien: unos sujetos las poseen y a otros les faltan. Si en un mercado hay alguien que sabe mucho y otros que no saben nada, las relaciones económicas no están equilibradas y no son eficientes (por ejemplo: este es el caso del mercado laboral, del mercado del crédito, del mercado de los seguros).

Cuarto. Además, los mercados tienen muchas imperfecciones: no siempre hay una verdadera competencia entre las empresas, al contrario, prevalecen empresas monopolistas que pueden aprovecharse de su posición para ganar más; no siempre el acceso al mercado es posible para todos y se encuentran obstáculos en la entrada; etc. Todos estos casos nos hacen entender que no siempre la "mano invisible" equilibra mágicamente las cosas. Pero, no podría ser diferente. Permítanme una consideración de tipo antropológico: çcómo es posible que la suma de los egoísmos individuales produzca un bienestar general?

\section{El estado como remedio a los fracasos del mercado y los fracasos del estado}

Cuando los economistas y los políticos se dieron cuenta de los limites del mercado, la solución que imaginaron fue la dilatación del papel del estado. 
Desde el periodo entre las dos guerras mundiales, en todo el mundo el estado empezó a ocuparse de economía (directa o indirectamente), de educación, de salud, de cultura, etc. El fin declarado era remediar un mercado ineficiente, pero con el modelo del welfare state (estado de bienestar, estado social) el fin se volvió en la gestión de actividades que las empresas y los individuos pueden desarrollar muy eficientemente, pero el estado las hace para conseguir un control político, social y cultural de la sociedad.

En conclusión, el estado como también el mercado no es eficiente, ni tampoco justo y equilibrado. ¿Por qué el estado fracasa?

Primero. No siempre los politicos y los funcionarios públicos toman decisiones y tienen comportamientos correctos, al contrario, a veces se aprovechan de su posición de poder para conseguir más poder y también ganancias ilegales. Estos comportamientos son más probables si el papel del estado es muy amplio.

Segundo. $\mathrm{Si}$ es verdad que no siempre las decisiones tomadas gracias al mecanismo del mercado, es decir, a través de los precios, son racionales, çcómo es posible que decisiones politicas tomadas sin mecanismos que no tengan una sólida base objetiva sean más racionales y eficientes?

Tercero. El sector público es mucho más burocratizado que el sector privado. La presencia de la burocracia no elimina la asimetria informativa, al contrario, hay funcionarios que saben mucho y ciudadanos que están en una posición de inferioridad muy grande.

Cuarto. Si el estado dilata su actividad necesita más recursos y, por lo tanto, pide más impuestos, sustrayendo recursos a las empresas privadas y a los particulares que podrian usarlos más eficientemente.

Quinto. En la lógica del mercado el objetivo es económico (el provecho propio). En la lógica del estado el objetivo es político, es decir, el crecimiento del poder, lo que implica una lógica que no es económica. Muy probable que asenso político y parsimonia no estén de acuerdo.

Sexto. No siempre las decisiones tomadas según el principio de la mayoría son verdaderamente democráticas. Hay una paradoja muy famosa, conocida como la paradoja de la mayoría. Supongamos que tenemos que hacer un sondeo para saber cuales son los colores favoritos por la mayoria de la gente. Entrevistamos tres personas: A, B y C. A prefiere el blanco al negro y al amarillo, mientras que a B le 
gusta más el amarillo que el blanco y el negro, $\mathrm{C}$ indica en el orden negro, amarilla y blanco. Bueno, entre el blanco y el negro, la mayoría prefiere el blanco; entre el negro y el amarillo el favorito es el negro. Por lo tanto, se podría concluir que el orden de preferencia por la mayoria es el siguiente: blanco, negro, amarillo. Al contratio, $\mathrm{B}$ y $\mathrm{C}$ prefieren el amarillo al blanco (jes todavia la mayoría!).

Séptimo. El desarrollo del estado social, como ya dicho, implica el uso de recursos económicos para brindar servicios que muchas veces no tienen una calidad alta y que, además, cuestan mucho. La experiencia de los países más desarrollados enseña con mucha evidencia las contradicciones de este modelo de estado.

\section{4. ¿Hay algo entre el estado y elmercado?}

Como hemos visto, el mercado fracasa y el estado no es un buen remedio. ¿Es posible encontrar algo alternativo entre estado y mercado? ¿Qué más hay?

La respuesta es fácil: está la economía y la sociedad, donde no se encuentran engranajes anónimos, por un lado, y súbditos o esclavos, por el otro. Al contrario, se encuentran personas y empresas, con su identidad y sus relaciones.

Si observamos lo que los sujetos hacen, nos damos cuenta de la existencia de formas de organización y reglamentación económica que son diferentes de las relaciones de mercado y de las organizaciones públicas.

En sintesis hay dos tipos de fenómenos:

Primero. Las empresas concluyen acuerdos y alianzas entre ellas para reducir la incertidumbre y el riesgo del mercado. Así, permanece todavia el mercado, pero a lado - y complementaria - hay una zona gris de relaciones que no están gobernadas por las reglas del mercado sino por las reglas que ellas mismas dictan, La regla en este caso surge del interior de la vida de las empresas. Además, las alianzas estratégicas nacen para durar en el tiempo. Una alianza permite a todas las empresas que crezcan (al extranjero también) sin modificar radicalmente su tamaño y por lo tanto sin invertir todo el dinero que seria necesario en caso de crecimiento de dimensión.

Segundo. Por otro lado, se encuentran en la sociedad iniciativas que nacen del deseo compartido por muchas personas de hacer algo sin un fin de utilidad inmediata, sin ganancia económica, simplemente a partir del deseo de hacer algo útil para los demás. 
La historia de la Iglesia, de la comunidad cristiana, tiene una riqueza extraordinaria en este sentido: hospitales, escuelas, universidades, etc., siempre han sido creados como resultado de un encuentro entre las infinitas necesidades del pueblo y el deseo de utilidad de la vida de algunos. No estoy hablando de simples actividades caritativas: me refiero a iniciativas económicas que son verdaderas empresas (empresas no lucrativas). Estas iniciativas tienen valores y reglas que nacen de los que las están construyendo y las reglas tienen el fin de garantizar orden, equilibrio, lealtad, justicia, verdad, responsabilidad.

Si retomamos los motivos de fracasos del estado y del mercado, nos damos cuenta que, sean las alianzas o las empresas no lucrativas, pueden ser una respuesta muy eficiente a los fracasos mismos. Por ejemplo, tomemos el caso de una familia que tiene un abuelo enfermo: el estado puede dar respuesta a esta necesitad, pero solo organizando actividades muy costosas, no siempre eficientes ni eficaces. $\mathrm{La}$ experiencia y el sentido común también nos dicen que la respuesta a una necesidad es tanto más puntual cuanto más no es un mecanismo impersonal que va a brindat el servicio, sino los que viven más cerca de la persona. En nuestro ejemplo, significa que la respuesta a la necesitad del abuelo sale mejor si no es una institución pública que se ocupa de él, sino su familia misma (la municipalidad o el estado podrían intervenir para apoyar, capacitar y financiar la familia).

La doctrina social de la Iglesia habla del principio de subsidiariedad para expresar esta idea.

\section{La economía y la sociedad deberían crear las reglas del estado y del mercado}

En conclusión, la observación de la realidad de la economía nos sugiere que los individuos saben construir iniciativas económicas y sociales, saben poner reglas que facilitan su desarrollo, saben reglamentar sus relaciones de intercambio de bienes e informaciones. Entonces, no necesitan un estado que dicte reglas de convivencia para hombres que no saben relacionarse y socializarse, como si fueran niños. Al contrario, necesitan un marco normativo que facilite el libre crecimiento de relaciones humanas, porque estas son un recurso fundamental para el desarrollo de un país: así se construye el bien común.

¿Cómo tiene que ser planteada la relación entre estado, mercado c iniciativas de la sociedad? La sociedad tiene que crear el mercado y el estado tiene que favorecerlo y ayudarlo; estamos hablando de un proceso que tiene que ser desarrollado, de una construcción. En efecto, el mercado no puede nacer 
espontáneamente ni auto fundarse: el mercado es libre si hay libertad (no es al contrario). El mercado es condición necesaria pero no suficiente para la existencia de la democracia. No es el mercado que hace libres a las personas y a las empresas, la libertad es un proceso que se desarrolla en el ámbito de las relaciones personales y políticas. En este ámbito los valores de uso prevalecen sobre los valores de cambio. En las relaciones entre las personas aparecen valores como dones, en el ámbito público los valores ( $\mathrm{y}$ bienes) comunes. Estos no son valores que se sitúan al lado de la economia.

Desde este punto de vista, el mercado tiene que ser proyectado y construido como estructura de comunicación entre individuos libres, pera imperfectos, que toman la responsabilidad y se encargan de la tarea de buscar a través de la compra y de la venta de bienes y servicios la respuesta más adecuada (oferta) para sus necesidades (demanda).

El asunto de las reglas del mercado tiene que ser planteado de esta manera. Las reglas deben desarrollar y fortalecer el crecimiento de la libertad de construir iniciativas económicas y sociales, expresión de la capacidad de relacionarse de todos los sujetos.

¿Cómo tienen que ser estas reglas? Un buen mercado necesita pocas reglas y controles eficaces (no vejatorios).

$\mathrm{Si}$, por un lado, no basta el mercado (en efecto muchas veces la libertad que el mercado garantiza es la libertad de actuat en contra de los demás), por otro lado - como la imperfección no está en el mercado sino en los hombres que actúan tenemos que evitar el error contrario, es decir, no puede ser que todo se solucione porque otros hombres, igualmente imperfectos, pero en el marco del estado, se sustituyan a los particulares dictando reglas abstractas.

En conclusión, querria decir unas cosas:

Primero. La creación de reglas económicas (y sociales) no deberia ser el resultada de un proceso vertical sino de un proceso horizontal y plutalista. Diferentes sujetos tienen que ser responsables para la creación de las reglas de sus relaciones.

Segundo. No es necesario un sin número de reglas. Al contrario, la economía es más eficiente si las reglas son pocas y claras.

Tercero. Las reglas tienen el fin de valoriza y favorecer, no el fin de reprimir lo que nace en la sociedad.

Cuarto. La escasez de las reglas tiene que ir junto a la rigurosidad de los controles. 
En sintesis, se necesitan reglas que favorezcan la transparencia, la circulación de las informaciones, la subsidiariedad, la igualdad de las oportunidades, la no-arrogancia y la solidaridad entre las generaciones.

Dra. Clara Caselli Coordinadora de la Facultad de Ciencias Económicas y Comerciales Universidad Católica Sedes Sapientiae

\section{Bibliografia}

Este artículo es el resultado conjunto del trabajo cientifico y de la amistad de un grupo de economistas generales y economistas de empresa italianos (al cual el Autor del presente artículo estaba incorporado) que discutieron el tema desde los años 1994-1995. De este trabajo salieron muchos artículos contenidos en la revista "Persone \& Imprese", en particular dos números monográficos: "Construir el mercado" (n.2 1995), "Mercado y mercados" (n.3 1995).

Para estudiar a fondo el tema, señalamos los textos siguientes:

Williamson O.E.,

L'organizzazione economica: imprese, mercati e controllo politico,

IIMulino, Bologna 1991

LazonickW. H.,

L'organizzazione delle imprese e il mito dell'economia di mercato,

II Mulino, Bologna 1993

Bowles S., Gintis H.,

Gustafsson B., Markets and democracy: Participation, Accountability and Efficiency, Cambridge University Press, Cambridge 1993

Egidi M., Marris R.,

Economics, Bounded rationality and Cognitive Revolution, Elgar, Aldershot 1992

\section{ZamagniS.,}

The Economics of Altruism, Elgar, Aldershot 1995

Wolf C., Mercato o stato: una scelta tra alternative imperfette, Giuffré, Milano 1995 